\title{
Research on Competitive Strategies of Telecom Operators in Post-3G Era Based on Industry Chain Value Stream
}

\author{
Zhong Wei, a, Wang Jianming ${ }^{2, b}$ and Zhang Yang ${ }^{3, c}$ \\ ${ }^{1}$ Beijing University of Posts and Telecommunications, Beijing 100876, PRC \\ ${ }^{2}$ Institute of China Unicom, Beijing 100032, PRC \\ ${ }^{3}$ Institute of China Unicom, Beijing 100032, PRC \\ azhongwei1@chinaunicom.cn, ${ }^{b}$ wangjm170@chinaunicom.cn, ${ }^{c}$ zhangyang115@chinaunicom.cn
}

Keywords: Industry Chain, Value Stream, Telecom Operator, Post-3G era

\begin{abstract}
This paper systematically analyzes the evolution of telecom industry chain, and builds a telecom industry chain value stream model. Besides, the article presents a competitive strategy model of telecom industry chain, which is based on the telecom operators' perspective on maintaining the dominance in the chain.
\end{abstract}

\section{Preface}

From a global perspective, 3G networks and services were relatively mature, and user acceptance has also reached a higher level. Substantial progress has been made by the subsequent network evolution, and the number of the carriers which deployed LTE is rapidly increasing. Considering domestic situation, the $3 G$ service types and number of customers are growing rapidly. Hence, the three major domestic carriers are actively promoting the evolution of $3 G$ network. Due to the upgrade of network and the enrichment of mobile internet service in Post-3G era, the telecom industry chain will be more complicated, and the competition will be even more intensive.

\section{Analysis of Telecom Industry Chain in Post-3G Era}

2.1. Traditional Telecom Industry Chain. In traditional telecom industry era, telecom operators mainly provide basic telecom services, which are voice-based, relatively simple and also completely dependent on telecom network. All telecom services are provided by telecom operator alone, and all revenues remain with the telecom operator. Telecom industry chain is a single linear industry chain including members of network equipment providers, system integrators, basic telecom operators, terminal providers, and end customers (as shown in Fig.1). Among them, network equipment providers are responsible for providing network hardware equipment, system integrators are responsible for providing software platform, basic telecom operators are responsible for building and operating the basic network, terminal manufacturers are responsible for providing terminal devices, such as mobile phones and fixed telephones, customers are in the end of industry chain and are the end users of the service.

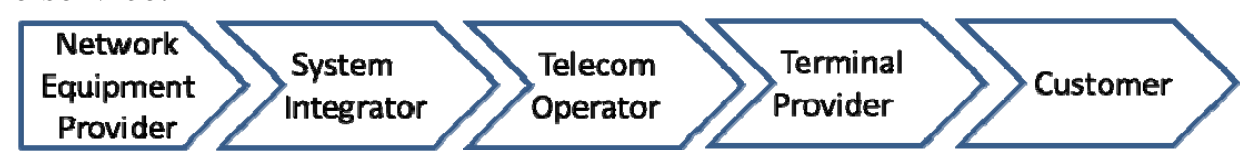

Fig. 1 Traditional Telecom Industry Chain

The traditional operator-centered telecom industry chain is consistent with the fundamental position of telecom industry. It contributes to unify technical standards and get scale merit of telecom network. The main features of the traditional telecom industry chain are as follows. First, monopolize. The participants and intermediate links of telecom industry chain are comparatively little, and the entry threshold for telecom industry is rather high, so that the chain became closed and highly monopolized. Second, single linear. The links among the industry chain are simple, namely, a single 
linear relationship. The industry chain is vertical relationship which is from the upstream to the downstream. Third, technology oriented. The telecom market is sellers' market, and the influence of technology advances is more important than market-driven on the development of telecom industry.

Due to the enhancement of 3G network capabilities, the development of sequent evolution of technology and the proliferation of mobile data services, telecom operators also took part in the content, service providing as well as other similar fields in industry chain. Thus, the telecom industry chain formed a multi-dimensional interaction situation, also brought a challenge to the telecom operator's leading status.

2.2. Telecom Industry in Post-3G era. In Post-3G era, some significant changes occur in the structure of the telecom industry, and the most prominent feature is the evolution from single linear structure to mesh structure. The value center of telecom industry chain is shifted, and the value stream becomes more complex. Telecom operator's relationship with relevant industries is enhanced, and the telecom industry chain also becomes more dynamic and open.

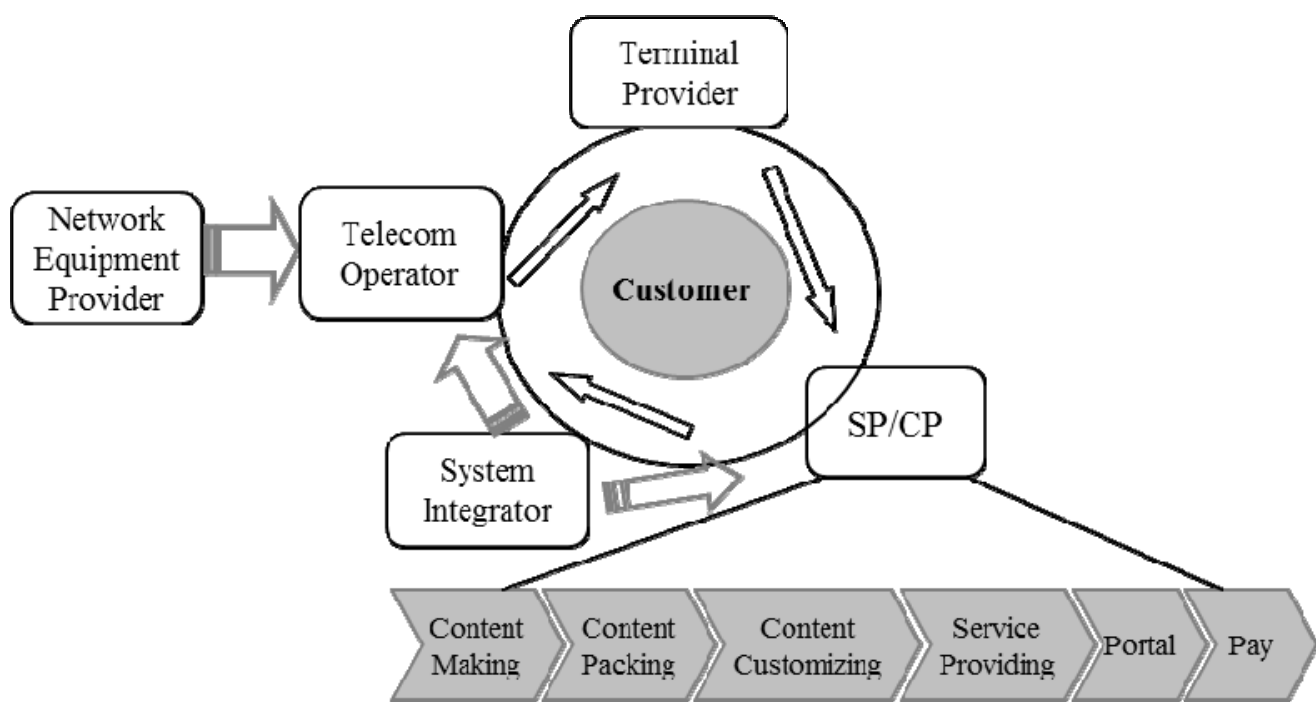

Fig. 2 Mesh Structure of the Telecom Industry

The industry chain becomes mesh structure. There are further fissions in telecom industry chain links, and the division of functions becomes more detailed and explicit. From the longitudinal aspect, the number of new entrants to telecom industry chain is gradually increasing. For example, content providers subdivided into content producing, packaging, customizing and so on. From the lateral aspect, the enterprises at the same link in the industry chain experienced an obvious increase in the number, and became more professional. Industry chain cooperation transferred from the simple value provided to senior cooperation mode, such as strategic alliances, complementary advantages, resource sharing, process connection and other similar senior modes.

The value center of the industry chain is transferred. The contribution to value creation of each link in telecom industry chain is redefined, moreover, the value and profit of the industrial chain is transferred. Resources are gathering to the links which play critical role during value creation, and the scope of shift becomes bigger and bigger, the way of shift becomes more and more diverse. The value of pure pipe decreases gradually, and the contents and applications becomes more and more important. The center of gravity of telecom industry's value transferred to the enterprises which have critical abilities such as customer control and resource integration. According to the statistics of "Analysis International Consulting Company", the percentage of mobile data traffic revenue of mobile internet revenue continuously declined in the second quarter of 2012 in china, the rate of mobile data traffic revenue was $29.67 \%$, which was lower than that of the mobile shopping (40.06\%). While, it was slightly higher than that of the mobile applications and service (25.92\%), and the remaining $4.34 \%$ was wireless advertising revenue. 
The correlation between telecom industry and others is strengthened, and the industry chain becomes dynamic opening. As the telecom service continuously penetrates into all fields of daily life, business integration between telecom industry and other industries becomes deeper and deeper. The trend of alternative and the overlap relation among industries are increasingly obvious. Along with the strengthening of the relationship, reasonable settlement system and profit distribution model become the core of the industry collaboration, and multi-win allocation mode ensures the smoothly implement of the cross-industry business. At the same time, the telecom industry chain is more open and the participants of telecom market are more complicated, forming a dynamic alliance which is composed of various industries. Thus, it makes telecom industry chain lack of long-term stable relationship, and more changeable. Overall, the telecom industry chain will be more dynamic and open.

\section{Value Stream of Telecom Industry Chain in Post-3G Era}

In Post-3G era, telecom operators are facing the alternative competition from internet enterprises on the aspects of business, resources, the business model and so on. Taking the application for example, the competition focuses on Mobile IM, Mobile Payment, Application Store, Mobile Search and other similar applications. The mobile applications, such as Mobile IM, occupy mobile network signaling and data channel for long hours, replace SMS and voice services, and make telecom operators face the danger of being “dump pipe”.

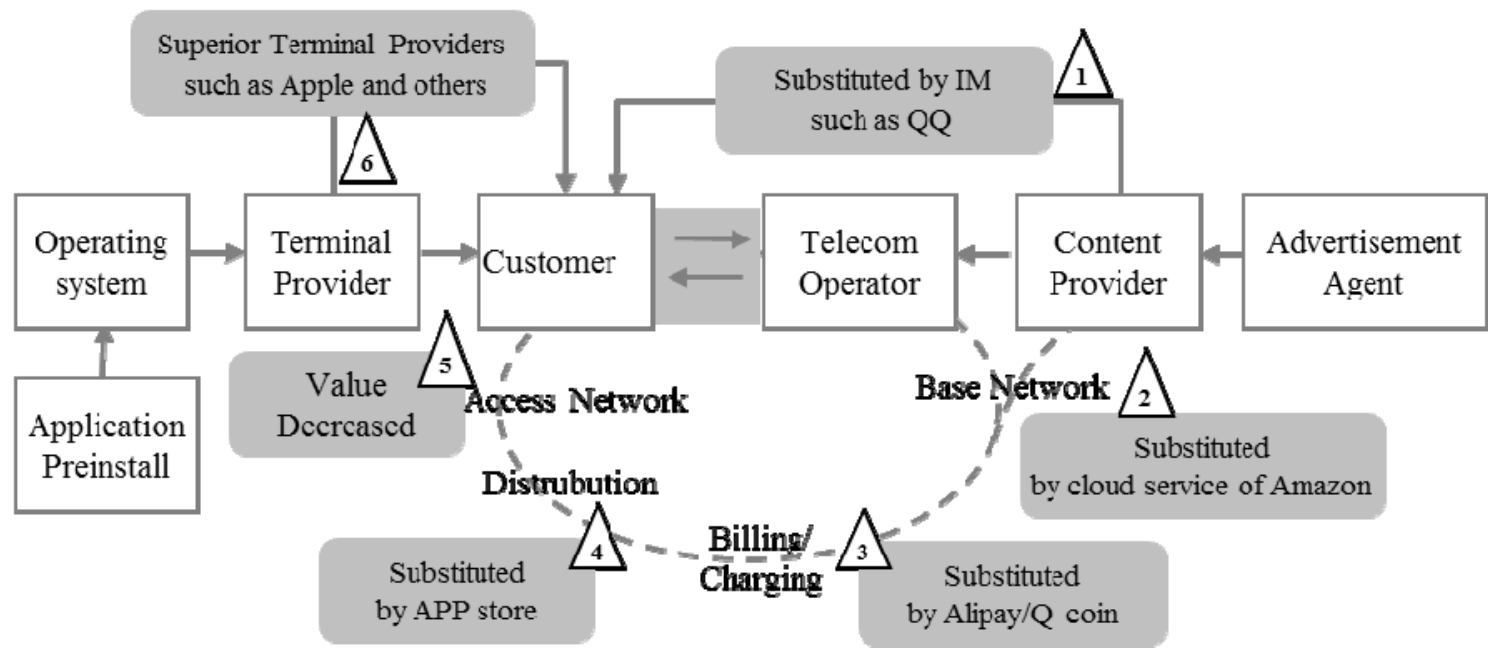

Fig. 3 Telecom Industry Chain Value Stream Model

Overall, the role of the industry chain is being substituted, and the value in the industry is decreasing, thus making telecom operators face enormous threats.

First, the voice service is substituting by IM. Besides, the basic network services such as access service are also facing the threat of being substituted. For these reasons, the value of traditional telecom is decreasing gradually. (Fig. 3, joints $\triangle \triangle 2 \triangle 5$ ).

Second, leading terminal providers such as APPLE and internet enterprise such as GOOGL had established new monopoly in the fields among software develop, terminal produce, content provide and so on, thus being the replacement of telecom operators (Fig. 3, joints 6 ).

Third, the industry chain is actively extensible and the value center is diversified. Moreover, telecom operators are facing more and more alternative threats in billing, charging, distribution channel, and other fields. (Fig.3, joints $\angle \mathbf{S} / \mathbf{A}$ )

\section{Competitive Strategies of Telecom Operators}


Based on the telecom industry chain value mode and the six main value stream joints, there are four main strategies which telecom operators can adopt: network evolution, terminal customizing, industry chain cooperation and platform mode.

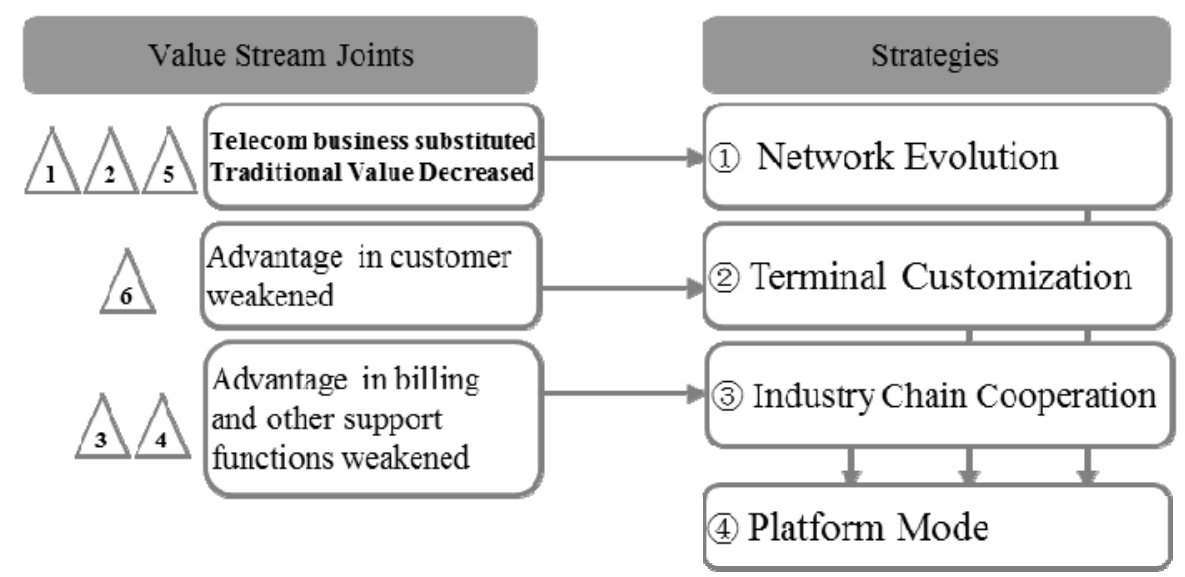

Fig. 4 Strategies of Telecom Operators Based on Value Stream Mode

These four strategies are interrelated and interdependent for telecom operators. The evolution and upgrade of network is the foundation of other strategies, and it is helpful for keeping the core competence of telecom operators. Based on the advantages of network, enormous customers and other resources, telecom operators are able to cooperate with terminal providers and content providers which are in the upstream and downstream of telecom industry chain, construct a stable industry chain alliance, and obtain integrated competitive advantages. In the future, along with the continuous emergence of new businesses and competition from different industries, telecom operators need to continuously promote the transformation of the platform mode.

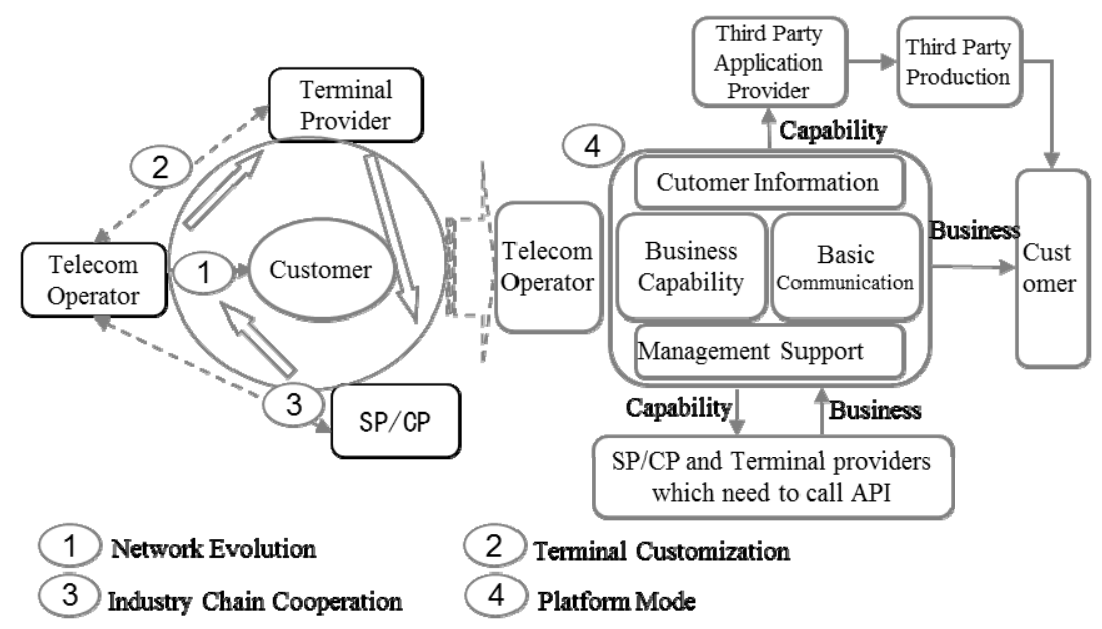

Figure 5 Competitive Strategies of Telecom Operators in Post-3G era

First, telecom operators must continuously upgrade network and improve network intelligent level. Telecom network is operator's core resource, the lifeline for survival and the foundation of cooperating in the industry chain. At the same time, on the premise of the improvement of terminal processing capability and the enrichment of services and applications, network access capacity becomes the key factor of customer experience. Therefore, telecom operators need to further improve network coverage, accelerate network upgrade, enhance network intelligent level (such as the controllability and manageability of the network), so as to provide necessary conditions of innovating network operation mode and improving cyber source value. Network evolution strategy enables telecom operators to be the main driving forces of the telecom industry as well. 
Second, telecom operators should actively promote terminal customization and business built-in. Telecom operators should carry out terminal business preinstall, grasping the user access to the mobile internet and providing customized services. At the same time, telecom operators should strengthen the cooperation with terminal manufacturers, promoting deep customization of mobile terminals and providing business development platform based on terminal capacity to control customers through the "terminal + service" model firmly.

Third, telecom operators should pay more attention to the cooperation among the members of telecom industry chain and the ability of resource integration. Cooperation should be carried out with SP/CP in multi-level actively, through building a benefit sharing and multi-dimensional cooperation mode, and forming a relatively stable strategic alliance. It can fully meet the customer's diversified and personalized demands to provide more subdivided products and services. To meet the demands of the participants in industrial chain and gather enough scale industrial capital, telecom operators should set up a value distribution pattern by negotiating, and create a good environment for value maintaining of the industry chain.

Fourth, telecom operators should insistently make innovations in business model and promote the platform operation. As the improvement of network capability and the growth of emerging innovative business, the trend of being dump pipe is more and more obvious for telecom operators. Telecom operators need to make the transition from the operation of basic telecom network and basic communications business mode to "platform mode" step by step. The platform operation would regard cyber source, business ability, support ability, customer resources and so on as the core factors, create a trading place to gather outstanding applications and enormous customers, and form a harmonious win-win ecology system. The platform operation is a systematic engineering. It not only needs telecom operators to open the basic communication ability and the professional business ability to the telecom industry, but also needs telecom operators to adjust their organizational structure and promote business model innovation to construct the real platform management system.

\section{References}

[1] Zhang Ke \& Lv Ting jie \& WuQi, Telecom Value-added Business, Beijing University of Posts and Telecommunications press, 2008.

[2] Wang Po \& Huang Xiu qing, Position Analyze and Strategy Research of Telecom Operator in 3G Industry Value Chain [J], Communications Management and Technology, 2006 (6).

[3] Xue Lihong, Zhang Yunhua, Cao Min, Research on essential factors about operation of mobile Internet and business model [J] , Telecommunications Science, 2009(5).

[4] Li Shuang, Long Xiao yu, The competition and cooperation strategy of content providers and service providers in the 3G industrial chain, Journal of XI'AN University of Posts and Telecommunications, 2009 (2).

[5] Li Yiming, Mobile Internet business model and typical cases [J] , Telecommunications Science, 2011 (7).

[6] Jin Yong sheng, Ying Jiang yong, Challenge and Strategies of telecom operators and the essence of Mobile Internet, Mobile Communications, 2012 (5). 